Original Research Paper

\title{
Fabrication and Mechanical Properties of Glass Fiber/Talc/CaCO 3 Filled Recycled PP Composites
}

\author{
${ }^{1}$ Uğur Soy, ${ }^{1}$ Fehim Findik, ${ }^{2}$ Salih Hakan Yetgin, ${ }^{3}$ Tolga Gokkurt and ${ }^{4}$ Ferhat Yıldırım \\ ${ }^{1}$ Department of Metallurgy and Materials, Sakarya University, \\ Faculty of Technology, Esentepe Campus, 54187 Sakarya, Turkey \\ ${ }^{2}$ Department of Manufacturing Engineering, Faculty of Simav Technology, Dumlupinar University, Turkey \\ ${ }^{3}$ Polipro Plastik San. ve Dıș Tic. A.Ş, R\&D director, Kocaeli/Turkey, Turkey \\ ${ }^{4}$ Department of Industrial Design Engineering, Faculty of Simav Technology, Dumlupınar University, Turkey
}

Article history

Received: 21-02-2017

Revised: 29-07-2017

Accepted: 12-08-2017

Corresponding Author: Salih Hakan Yetgin Department of Manufacturing Engineering, Faculty of Simav Technology, Dumlupinar University, Turkey

Tel: +90-274-513 7917

Fax: +90-274-513 7924

Email: hakan.yetgin@dpu.edu.tr

\begin{abstract}
Until now, recycling studies brought to the agenda after the rapid increasing of plastic materials in every area and causing those plastics to environmental pollution after discarding them following the utilization. The purpose of recycling plastic waste is to minimize environmental pollution and to create of new resources. To perform the present study, Recycled Polypropylene Granules (RPP) belonging to Polypropylene (PP) will be used in most particularly in the automotive and in the packaging industry finding application area behind the Low Density Polyethylene (LDPE). To develop the several properties (physical and thermal) of RPP polymer and to get close to or greater value to the original PP features, different rates of micron-sized glass fibers, talc and $\mathrm{CaCO}_{3}$ are added into the polymer. By recycling waste, demand for natural resources (such as oil, which is plastic's raw materials) will decrease and rapid consumption of energy sources will be prevented while providing the protection of natural resources. Raw materials imports would be reduced due to the usage of recycled products. In this study, Recycled Polypropylene Granules (RPP) were obtained from companies and glass fiber/talc/ $\mathrm{CaCO}_{3}$ additive RPP granules in different ratios were produced with compounding extrusion process. These produced new composite pellets were produced in injection molding machine by means of designed mold to perform tensile and impact tests. In the thermal analysis, the melting temperature and crystallization rate were determined by DSC analysis; the thermal decomposition temperature was determined by TGA analysis. Micro structural examination was done using a Scanning Electron Microscope (SEM).
\end{abstract}

Keywords: Recycling, Polypropylene, Fillers, Mechanical Properties

\section{Introduction}

Currently, environmental alarming has led to a renovated concern in usual materials and problems like recyclability and ecological care are happening gradually significant for the initiation of novel materials and artifacts (Arbelaiz et al., 2005). Trash is sensed as a main issue, particularly for vast expenditure polymers such as polypropylene (Brachet et al., 2008). Plastic recycling has been effectively applied with main treated materials causing in economic profits (Da Costa et al., 2007).

In the current study, recycled PP was used as a matrix for devising the composites. Recycled PP is obtainable as a trash material and generates many ecological harms.
To decrease the ecological harms, PP can be reprocessed to fabricate new value added artifact with little fabrication price (AlMaadeed et al., 2012). Due to its decent mach inability, excessive recyclability and little price, PP has been noticed a wide range of claims in the textile, packaging, car and furniture productions. To enlarge the variety of claims, growing the strength and modulus of PP has revived significant concern. Discharging PP with hard inert specks is an operative, inexpensive and suitable method to increase the strength and stiffness (Zheng et al., 2009).

Generally, the mechanical properties of recycled mixed polymers are evidently developed by summing fibres have ample greater strength and rigidity than those 
of the matrices (Homkhiew et al., 2013). In this study we used glass fibre, calsite and talc as reinforcement for making the composites. Several authors have investigated the recycling of polypropylene (Beg and Pickering, 2008). Dintcheva et al. (2001) studied the influence of three dissimilar fillers specifically glass fibres, calcium carbonate and wood fibres with the polyolefin reprocessed plastic and reported that glass fibres overtakes others by growing its tensile modulus from 460 to $935 \mathrm{MPa}$ with $20 \%$ glass fibre. Nevertheless, the drop of elongation at break was detected. A comparable investigation was directed by Putra et al. (2009) on the influence of glass fibre, talc, wollastonite and gypsum on the mechanical properties of recycled-plastic composites. Both fillers and reinforcement displays growth in the toughness of the materials. Their investigation proved that glass fibres demonstrate the finest outcomes by refining its tensile and flexural strength by $30 \%$ and the important growth in modulus by $250 \%$ with the adding of $\% 30$ glass fibre. The addition of glass fibre from 10-30\% by weight results in considerable growth in elastic modulus, along with a rise in strength with abridged ductility (Xanthos et al., 1995). According to the Bank's article (Lawrence, 2006), it can be understood that with the adding of $30 \%$ glass fibres, the elongation of break can decrease from 25 to $2 \%$.

Another study conducted by Gupta et al. (1989) focused on the influence of high temperature on the tensile properties of unreinforced and reinforced PP. They observed brittle behavior at inferior temperatures whereas it displays ductile behavior at upper temperature. The results of the study further designates that there is a fall of in excess of $50 \%$ tensile strength for the temperature of 20 to $55^{\circ} \mathrm{C}$ for together reinforced and unreinforced specimens. Conversely, the decrease in together tensile strength and modulus at raised temperature is under that of unreinforced specimens comparing to the glass fiber reinforcements. The researchers further reported that with the increment of test temperature, the interfacial shear strength decreased for all composite specimens which could ascend either from a flagging of chemical bond or from the reduction of thermal stresses and the decreased of bond strength at the fibre-matrix interface.

The mechanical properties of recycled mixed plastic leftover with the glass fiber displays better development as detected by Xanthos and Narh (1998; AlMaadeed et al., 2012; Hugo et al., 2011; Putra et al., 2009; Dintcheva et al., 2001) have stated that the melt flow index decreases with the increment of the fiber content owing to the great weight and the increment of the viscosity of the composite. A comparable state was described by Hugo et al. (2011) who stated that because of high price and treating restrictions for the recycled composite, the extreme quantity of glass fiber which could be combined in the artifact is $30 \%$ by weight. In this study, recycled polypropylene granules (G-PP) were obtained from companies and glass fiber/talc/ $\mathrm{CaCO}_{3}$ additive G-PP granules in different ratios were produced with compounding extrusion process. These produced new composite pellets were produced in injection molding machine by means of designed mold to perform tensile and impact tests.

\section{Materials and Methods}

\section{Materials}

A Recycled Polypropylene Granules (RPP) obtained from the Polipro Company was used as the polymer matrix material having a density of $0.92 \mathrm{~g} / \mathrm{cm}^{3}$. Talc and $\mathrm{CaCO}_{3}$ additive materials have been obtained from the Omya Company. Commercially available glass fiber with 4.55 $\mu \mathrm{m}-1 \mathrm{~mm}$ average length and $2.9 \mathrm{~g} / \mathrm{cm}^{3}$ average density was used as reinforcement for making the composites.

\section{Composite Preparation}

Talc, $\mathrm{CaCO}_{3}$ and glass fibers filled recycling PP polymer composites are produced using Brabender twin screw extruder. The extruder temperature was used in the range of 190-230 ${ }^{\circ} \mathrm{C}$ for filled RPP. RPP samples were prepared for $30 \%$ of talc, $\mathrm{CaCO}_{3}$ and glass fiber. The polymers mixtures were extruded, cooled and then granulated. Test samples were prepared by Arburg injection molding machine.

\section{Morphological Analysis}

Morphological analysis was carried out with the utilization of a Scanning Electron Microscope (Nano SEM 650). The cross-sections of the samples were examined after tensile tests to investigated the fracture and bonding between fillers and matrix.

\section{Mechanical Testing}

\section{Tensile Properties}

The tensile tests were accomplished consistent with the ASTMD 638-02 standard, by utilizing a Universal Testing Machine at a crosshead velocity of $10 \mathrm{~mm} / \mathrm{min}$. The standard dimensions are $20 \mathrm{~mm}$ length, $12.5 \mathrm{~mm}$ width and $4 \mathrm{~mm}$ thickness. The Young's modulus was determined routinely by software, Lloyd-LC Instruments by choosing tangent technique. The tensile test direction was uniaxial and five samples were taken for the tensile test. In each case, five samples were tested and the mean value was declared.

\section{Impact Properties}

Notched Charpy impact tests were carried out with a impact tester with pendulum energy of $15 \mathrm{~J}$, according to ASTM D 256. All the reported values for the impact tests were the average values of 5 samples. 


\section{Thermal Testing}

\section{Differential Scanning Calorimetry (DSC)}

The RPP and RPP composites were analyzed by DSC using a thermal analyzer (Setaram-Labsys evo). The measurements were taken by keeping fixed heating ratio of $10^{\circ} \mathrm{C} / \mathrm{min}$ under nitrogen atmosphere. The crystallinity fraction $\left(X_{c} \%\right)$ of the RPP and RPP composites was determined by means of the subsequent equation:

$$
X_{c}(\%)=\left(\Delta H_{m} / \Delta H_{m}^{0} \times W_{\text {polimer }}\right) \times 100
$$

$W_{\text {polymer }}=$ The weight ratio of polymer matrix

$\Delta H_{m} \quad=$ The heat of fusion

$\Delta H_{m}{ }^{0} \quad=$ The heat of fusion of $100 \%$ crystalline PP (207.1 J/g) (Velasco et al., 2002; Wal et al., 1998)

\section{Thermo Gravimetric Analysis (TGA)}

Thermo gravimetric analysis (TGA) measurements were performed in nitrogen atmosphere using a SetaramLabsys evo instrument at a heating rate of $10^{\circ} \mathrm{C} / \mathrm{min}$.

\section{Melt Flow Index}

Melt Flow Index (MFI) is defined as the weight of the polymers in grams extruded in $10 \mathrm{~min}$ through capillary of specific dimensions by pressure applied through dead weight via piston. Melt flow index was conducted using a Ceast model machine. ASTM D1238Method A was applied for determining the MFI of the recycled polymers.

\section{Morphological Study}

The morphologies of talc, calcium carbonate and glass fiber reinforced polymer composites were examined by Scanning Electron Microscopy (SEM) on the fracture surface of the tensile specimens. The samples were covered with a thin film gold and analyzed at an accelerating voltage of $1.00 \mathrm{kV}$.

\section{Results and Discussion}

\section{TGA Analysis Results}

The Polypropylene (PP) polymer and talc, calcium carbonate and glass fiber reinforced polymer composites samples are given in Fig. 1 for thermal decomposition curves (thermo gram). While the temperature at which the degradation of the PP polymer of approximately $380^{\circ} \mathrm{C}$, talc, $\mathrm{CaCO}_{3}$ and glass fiber reinforced PP polymer composites begin to decompose at approximately $400^{\circ} \mathrm{C}$. The decomposition temperature depends on the type of additives increased on average by $5.2 \%$. Similar results for glass fiber and wood flour were obtained from recycled polypropylene reinforced hybrid composites (AlMaadeed et al., 2012). In this case, the additives were added to PP polymer improve to the thermal properties of polymer and demonstrating that provides possibility for use at higher temperatures. Analysis of results losses of mass in the PP polymer composites samples were found around $70 \%$.

\section{DSC Analysis Results}

In Table 1, the DSC analysis results are given for the samples of RPP polymer, RPP $+30 \%$ talc, RPP $+30 \%$ $\mathrm{CaCO}_{3}$ and $\mathrm{RPP}+30 \% \mathrm{GF}$ polymer composites. As seen from the table, the melting temperature $\left(T_{m}\right)$ and enthalpy $\left(\Delta H_{m}\right)$ and crystallization rate $\left(\% X_{c}\right)$ of RPP polymer and doped RPP composites was obtained. There is no difference in $T_{m}$ of RPP polymer composites. As seen from the table that crystallization degree of talc, $\mathrm{CaCO}_{3}$ and glass fiber reinforced RPP polymer composites was obtained lower than that of undoped RPP polymer. While crystallization degree of RPP polymer was obtained as $36.87 \%$, its crystallization degree was attained as $36.35,30.83$ and $29.74 \%$ with the addition of talc, $\mathrm{CaCO}_{3}$ and glass fiber, respectively. The fillers prevent the movement of the PP macromolecular chain and the macromolecular section from getting ordered position of the crystals. The fillers hinder development of crystallinity. Consequently, the $X_{c}$ of polymer composites are reduced (AlMaadeed et al., 2012).

\section{Mechanical Tests}

The Recycled Polypropylene (RPP) polymer, 30\% talc filled RPP, $30 \%$ calcium carbonate filled RPP and $30 \%$ glass fiber Reinforced Polymer (RPP) composite samples were given in Fig. 2 for tensile strength results. While tensile strength of RPP polymer was obtained as $30 \mathrm{MPa}$, its tensile strength decreased with the addition of talc and $\mathrm{CaCO}_{3}$ and attained as 23 and $20.6 \mathrm{MPa}$, respectively. The tensile strength of the RPP polymer decreased to $23 \%$ and $31 \%$ for talk and $\mathrm{CaCO}_{3}$ respectively. This behavior could be generally caused by the reduced interaction at the interface level between the fibers and the polymer matrix (Mutje et al., 2006). The tensile strength was obtained as $68 \mathrm{MPa}$ with the increment of $126 \%$ by the addition of $30 \%$ glass fiber into RPP. Similar results were also obtained by AlMaadeed et al. (2012; Beg and Pickering, 2008; Zheng et al., 2009; Serrano et al., 2014). 
Table 1. Melting temperature and \% crystallization rates obtained by DSC analysis results

\begin{tabular}{llll}
\hline & Melting temperature $\left({ }^{\circ} \mathrm{C}\right)$ & Enthalpy of melting, $(\mathrm{J} / \mathrm{g})$ & \multicolumn{2}{c}{ Crystallinity } \\
Sample & $\mathrm{T}_{\mathrm{m}}$ & $\Delta \mathrm{H}_{\mathrm{m}}$ & $\mathrm{X}_{\mathrm{c}}$ \\
\hline RPP & 165.74 & 76.363 & 36.87 \\
RPP-30\%Talc & 166.25 & 52.697 & 36.35 \\
RPP-30\%CaCO & 169.19 & 44.699 & 30.83 \\
RPP-30\%Glass fiber & 167.46 & 43.128 & 29.74 \\
\hline
\end{tabular}

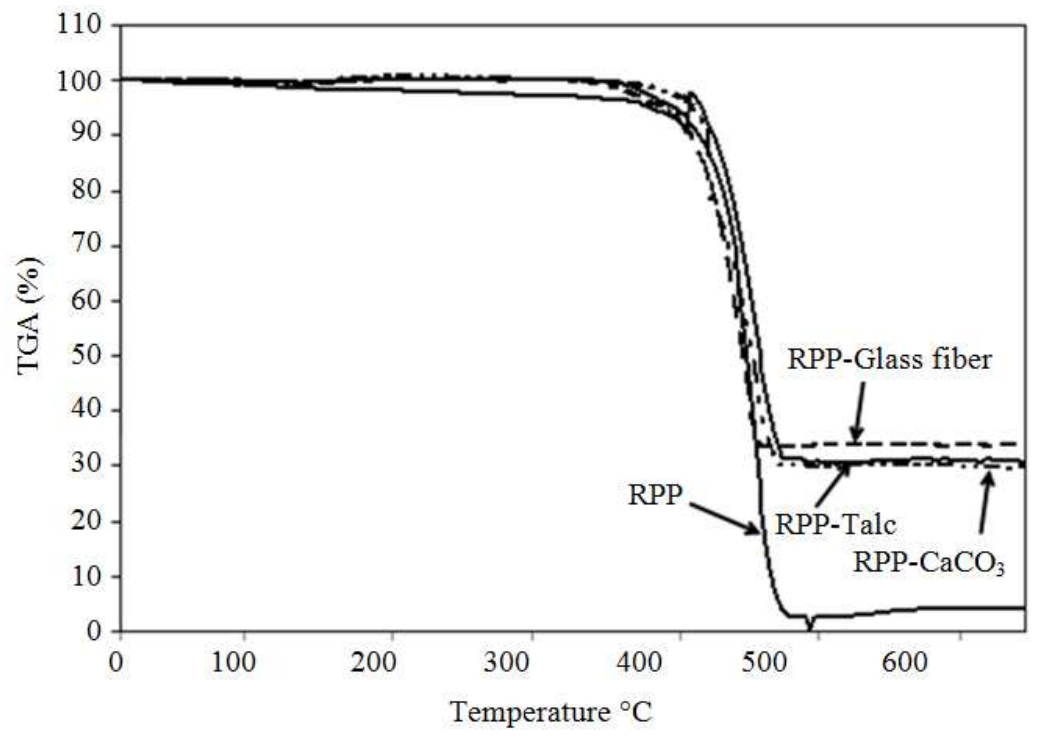

Fig. 1. TGA analysis results of RPP polymers and composites

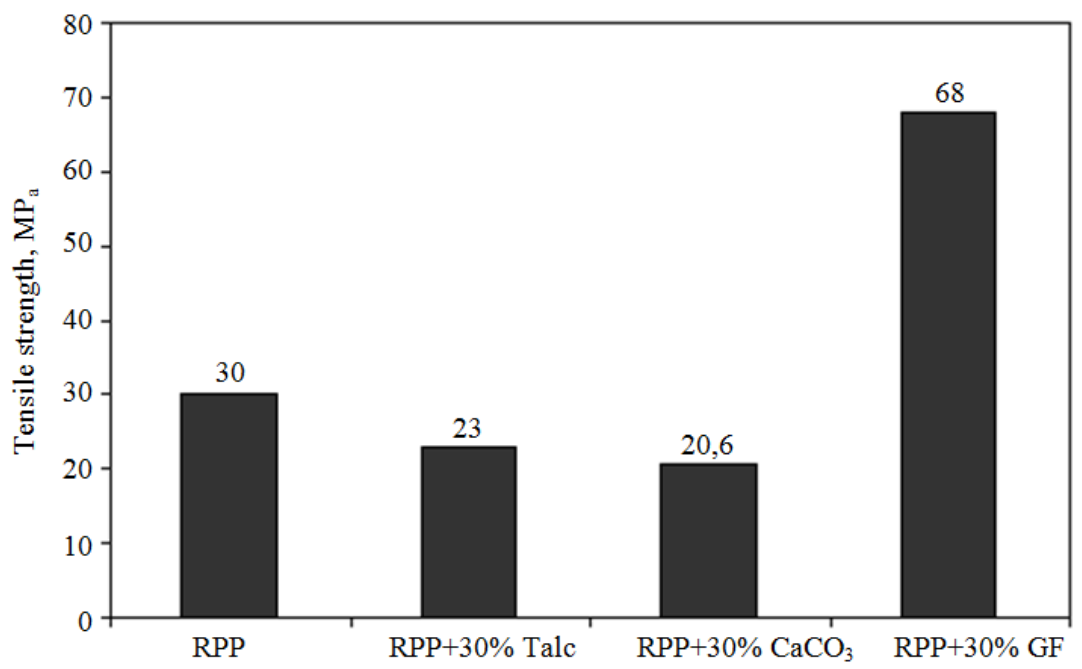

Fig. 2. Tensile strength of various polymeric samples of RPP, RPP+\%30 talc, $\mathrm{RPP}+\% 30 \mathrm{CaCO}_{3}$ and $\mathrm{RPP}+\mathbf{0} 30 \mathrm{GF}$

In Fig. 3, the yield strength results were given for RPP polymer, RPP $+30 \%$ talc, RPP $+30 \% \mathrm{CaCO}_{3}$ and $\mathrm{RPP}+30 \% \mathrm{GF}$ polymer composite samples. Similar to the results of tensile strength, the yield strength of RPP polymer decreased to 15.3 and $26.9 \%$ with the addition of talc and $\mathrm{CaCO}_{3}$, respectively. This is because; talc and $\mathrm{CaCO}_{3}$ additives are separated easily from the matrix due to the creation of a weak customization interface. The yield strength of GF reinforced composites is higher because it establishes a bond with the PP matrix at the same contribution rate. The yield strength of RPP $+30 \%$ GF polymer composite increased to $142 \%$ compared to the RPP polymer. Similar results were also obtained by Li et al. (2012) in the earlier work. 


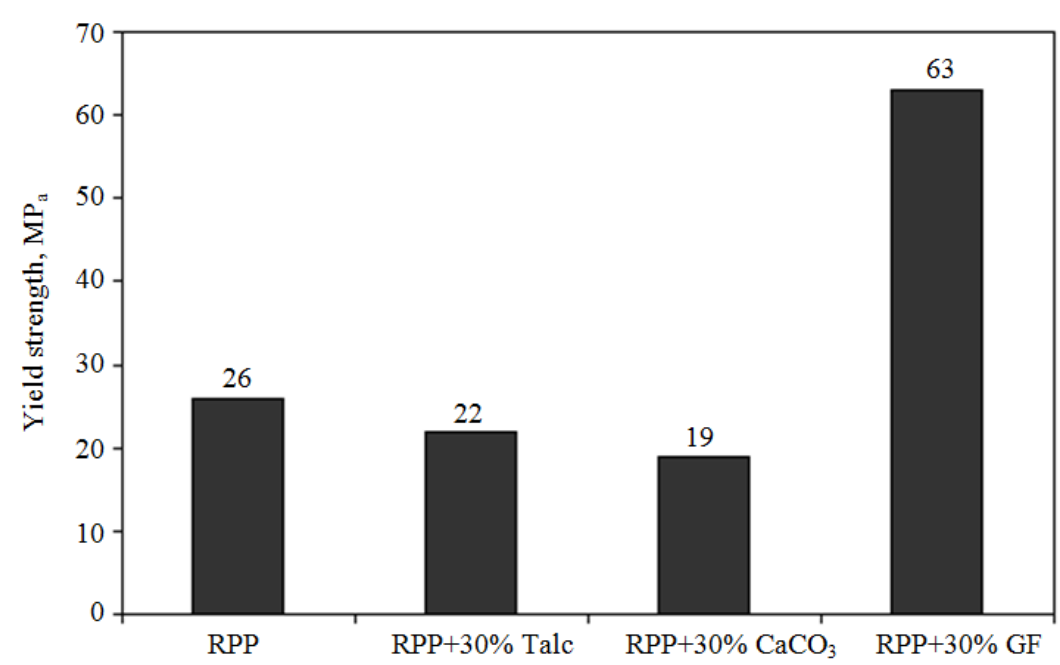

Fig. 3. The yield strength for the polymeric samples of RPP, RPP $+\% 30$ talc, $\mathrm{RPP}+\% 30 \mathrm{CaCO}_{3}$ and $\mathrm{RPP}+\% 30 \mathrm{GF}$

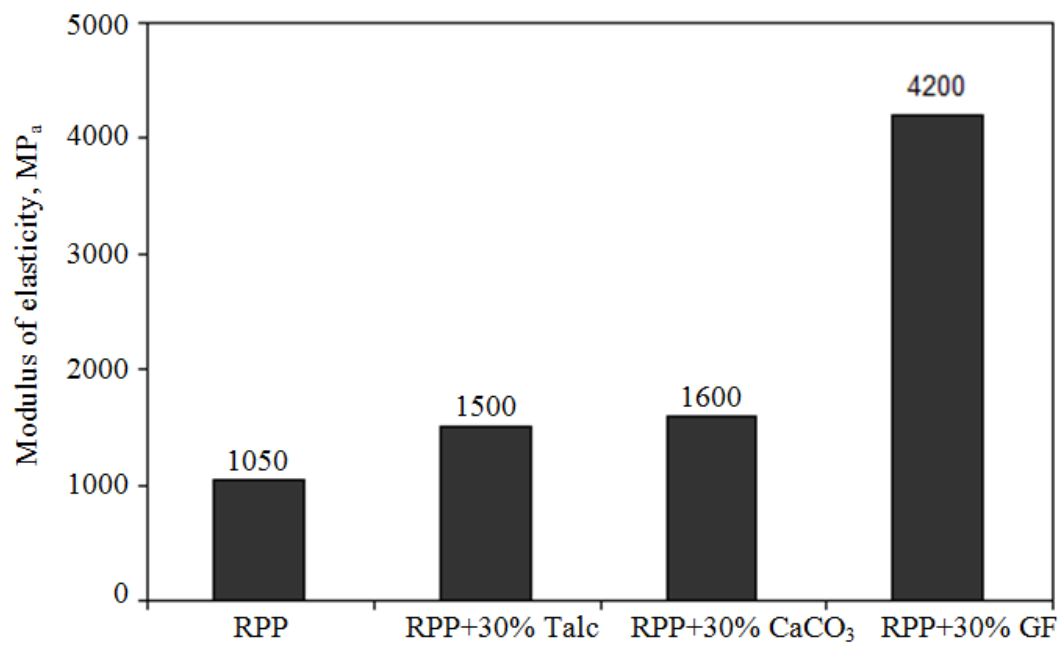

Fig. 4. The elastic modulus for the polymeric samples of RPP, RPP+\%30 talc, $\mathrm{RPP}+\% 30 \mathrm{CaCO}_{3}$ and $\mathrm{RPP}+\mathbf{0} 30 \mathrm{GF}$

In Fig. 4, the results for modulus of elasticity are given for the samples of GP polymer, RPP $+30 \%$ talc, $\mathrm{RPP}+30 \% \quad \mathrm{CaCO}_{3}$ and $\mathrm{RPP}+30 \quad \mathrm{GF}$ polymer composites. The modulus of elasticity increased with talc, $\mathrm{CaCO}_{3}$ and glass fiber into the RPP polymers. The $1 \mathrm{GPa}$ elastic modulus of RPP polymer increased in 42 and $52 \%$ and reaching to the values of $1.5 \mathrm{GPa}$ and 1.6 $\mathrm{GPa}$ with the addition of talc and $\mathrm{CaCO}_{3}$, respectively. By the accumulation of GF additives, the elastic modulus of RPP polymer increased to $300 \%$ and reaching to $4.2 \mathrm{GPa}$. The present results are consistent with the previous studies reported by (AlMaadeed et al., 2012; Beg and Pickering, 2008; Zheng et al., 2009 Serrano et al., 2014; Li et al., 2012).

In Fig. 5, the Izod impact strength results are given for the samples of RPP polymer, RPP $+30 \%$ talc, $\mathrm{RPP}+30 \% \quad \mathrm{CaCO}_{3}$ and $\mathrm{RPP}+30 \% \quad \mathrm{GF}$ polymer composites. The impact strength of GPP polymer decreased with the addition of talc and $\mathrm{CaCO}_{3}$; however the impact strength of GF increased. The impact strength (had $4.1 \mathrm{kj} / \mathrm{m}^{2}$ ) for RPP polymer was obtained as 3.2 and $3.5 \mathrm{kj} / \mathrm{m}^{2}$, respectively in case of using talc and $\mathrm{CaCO}_{3}$ additives, but these values were obtained as $8.8 \mathrm{kj} / \mathrm{m}^{2}$ with the addition of GF additives. Similar results were attained by the previous worker Beg and Pickering (2008).

Melt Flow Index (MFI) results are shown in Fig. 6. The MFI outcomes decreased with talc, $\mathrm{CaCO}_{3}$ and glass fiber materials. The viscosity of RPP composites increased as a result of the high content of the additives. Same results were observed by several researchers Beg and Pickering (2008; Lu et al., 2006). Tasdemir et al. (2009) studied the LDPE and PP-wood fiber composites and stated that MFI abridged with the growth of wood flour substance. Son et al. (2004) testified that MFI condensed with the growing of paper sludge substance. 


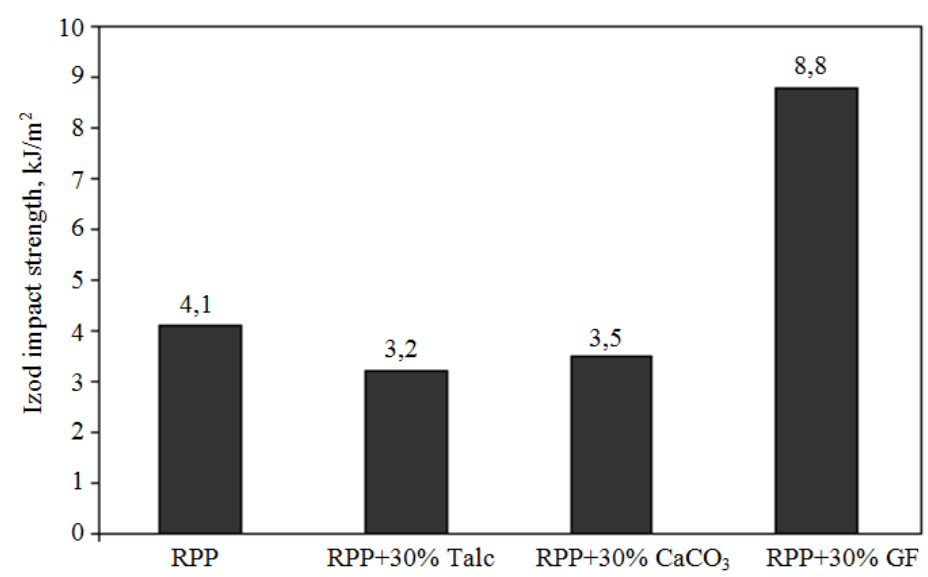

Fig. 5. The impact strength for the polymeric specimens of RPP, $\mathrm{RPP}+\% 30$ talc, $\mathrm{RPP}+\% 30 \mathrm{CaCO}_{3}$ and $\mathrm{RPP}+\% 30 \mathrm{GF}$

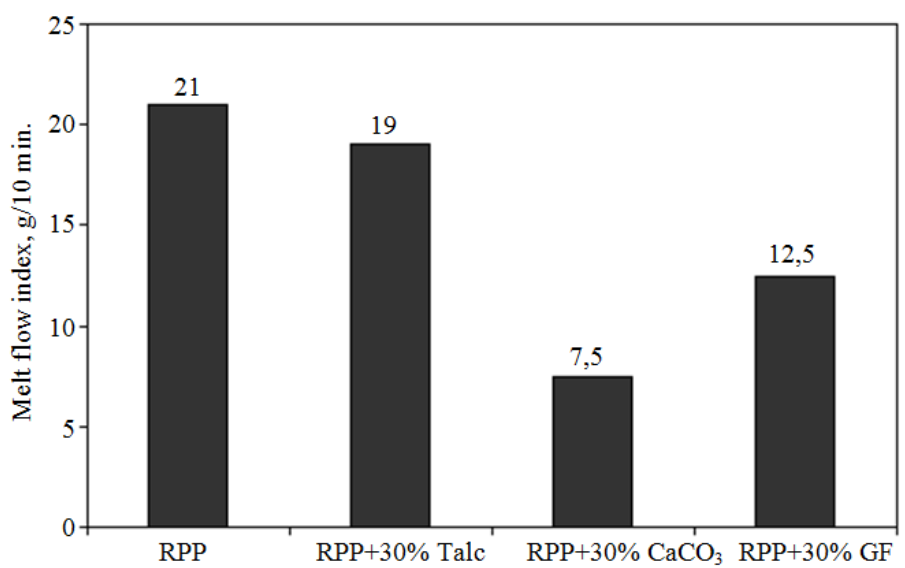

Fig. 6. The melt flow index values for the polymeric samples of RPP, RPP+\%30 talc, $\mathrm{RPP}+\% 30 \mathrm{CaCO}_{3}$ and $\mathrm{RPP}+\mathbf{0} 30 \mathrm{GF}$
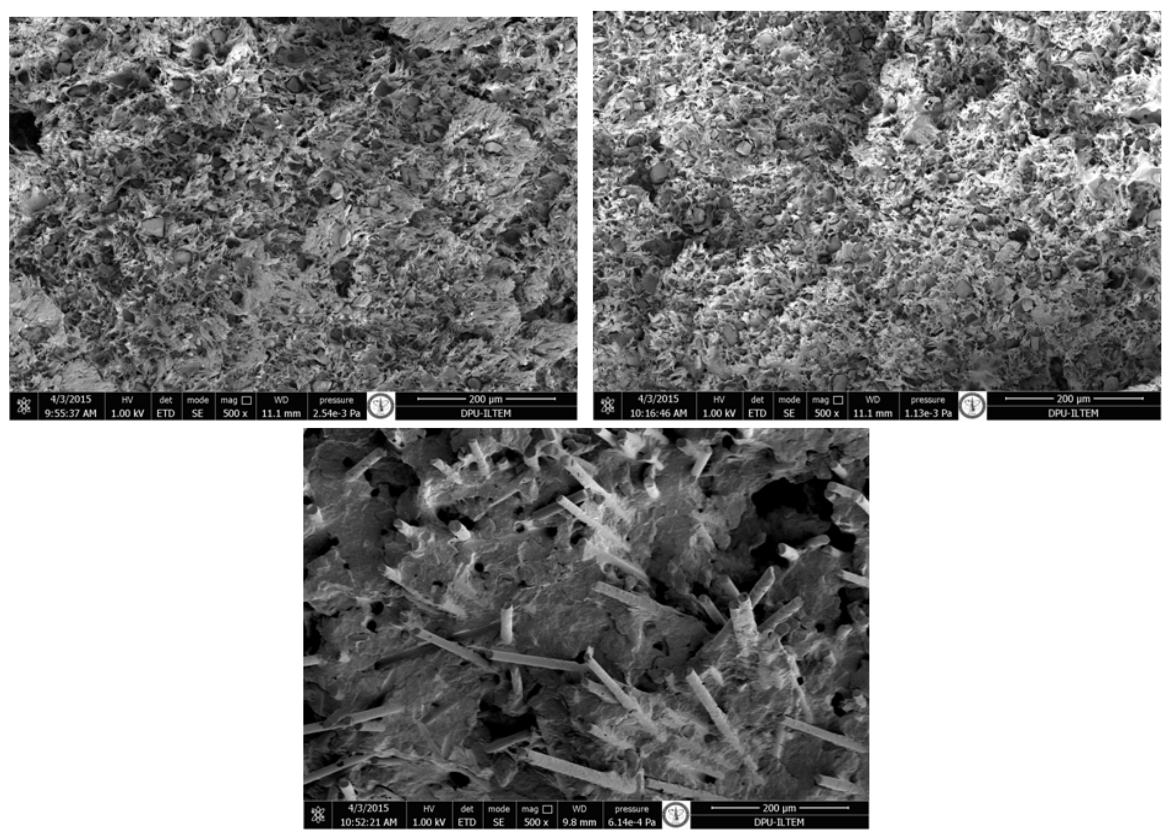

Fig. 7. SEM micrographs for the samples of (a) $\mathrm{RPP}+30 \%$ talc, (b) $\mathrm{RPP}+30 \% \mathrm{CaCO}_{3}$ and (c) $\mathrm{RPP}+30 \% \mathrm{GF}$ 


\section{Microstructural Characterization}

In Fig. 7, the SEM micrographs for RPP $+30 \%$ talc, $\mathrm{RPP}+30 \% \mathrm{CaCO}_{3}$ and $\mathrm{RPP}+30 \%$ GF were obtained from the fracture surfaces of the tensile specimens. As a result of the quite weak bonding between RPP and additives, RPP recycled polymers were pulled out from the talc and $\mathrm{CaCO}_{3}$ additives due to the high amount of talc and $\mathrm{CaCO}_{3}$ additives. However, the mechanical properties were developed for RPP $+30 \%$ GF polymers due to the both high amount of glass fibers and the better interface bonding between glass fiber and RPP matrix. It is seen from the SEM micrographs that the less glass fibers are pulled out and are broken. This situation shows strong bond interface evidence between glass fiber and RPP matrix.

\section{Conclusion}

In the present research, the following outcomes were obtained:

- The tensile strength of the RPP polymer reduced by 23 and $31 \%$ for talc and $\mathrm{CaCO}_{3}$, respectively. Also, the tensile strength was obtained $68 \mathrm{MPa}$ with the increment of $126 \%$ by the addition of $30 \%$ glass fiber into RPP

- The yield strength of RPP polymer decreased to 15.3 and $26.9 \%$ with the addition of talc and $\mathrm{CaCO}_{3}$, respectively. In contrast, the yield strength of GF reinforced composites was higher because it established a bond with the PP matrix at the same contribution rate. The yield strength of RPP $+30 \%$ GF polymeric composite increased to $142 \%$ compared to the RPP polymer

- The modulus of elasticity was increased with talc, $\mathrm{CaCO}_{3}$ and glass fiber into the RPP polymers. The $1 \mathrm{GPa}$ elastic modulus of RPP polymer increased in 42 and 52 and reaching to the values of 1.5 and 1.6 $\mathrm{GPa}$ with the addition of talc and $\mathrm{CaCO}_{3}$ respectively. By the accumulation of GF additives, the elastic modulus of RPP polymer increased in $300 \%$ and reaching to $4.2 \mathrm{GPa}$

- The impact strength of RPP polymer decreased with the addition of talc and $\mathrm{CaCO}_{3}$; however the impact strength of GF increased. The impact strength (had $4.1 \mathrm{kj} / \mathrm{m}^{2}$ ) for RPP polymer was obtained as 3.2 and $3.5 \mathrm{kj} / \mathrm{m}^{2}$, respectively in case of using talc and $\mathrm{CaCO}_{3}$ additives, but these values were obtained as $8.8 \mathrm{kj} / \mathrm{m}^{2}$ with the addition of GF additives

- The MFI outcomes decreased with talc, $\mathrm{CaCO}_{3}$ and glass fiber materials. Viscosity of RPP composites increased as a result of the high content of the additives

- As a result of the quite weak bonding between RPP and additives, RPP recycled polymers were pulled out from the talc and $\mathrm{CaCO}_{3}$ additives due to the high amount of talc and $\mathrm{CaCO}_{3}$ additives.
However, the mechanical properties were developed for RPP $+30 \%$ GF polymers due to the both high amount of glass fibers and the better interface bonding between glass fiber and RPP matrix. Strong bond interface evidence was observed between glass fiber and RPP matrix

\section{Acknowledgement}

The authors would like to thank to Scientific Research Projects Unit of Sakarya University due to the subsidy during the present study (Project number: 2014-09-08-001).

\section{Author's Contributions}

Uğur Soy: Literature search, checked tables and figures and interpretated the data.

Fehim Findık: SEM analysis, checked the gramatical errors, writing and revising of the manuscript.

Salih Hakan Yetgin: Mechanical and thermal tests, writing and revising of the manuscript, corresponding author.

Tolga Gökkurt: Supply material, Manufacturing of composites with extrusion and injection.

Ferhat Yıldırım: Manufacturing of composites with extrusion and injection, DSC and TGA analysis.

\section{Ethics}

The present work is not published in its present form in any journal or will not be published in any journal.

\section{References}

AlMaadeed, M.A., R. Kahraman, P.N. Khanam and N. Madi, 2012. Date palm wood flour/glass fibre reinforced hybrid composites of recycled polypropylene: Mechanical and thermal properties. Mater. Design, 42: 289-294. DOI: $10.1016 /$ j.matdes.2012.05.055

Arbelaiz, A., B. Fernandez, J.A. Ramos, A. Retegi and R. Llano-Ponte et al., 2005. Mechanical properties of short flax fibre bundle/polypropylene composites: Influence of matrix/fibre modification, fibre content, water uptake and recycling. Composites Sci. Technol., 65: 1582-1592.

Beg, M.D.H. and K.L. Pickering, 2008. Reprocessing of wood fibre reinforced polypropylene composites. Part I: Effects on physical and mechanical properties. Composites Part A: Applied Sci. Manuf., 39: 1091-1091. DOI: 10.1016/j.compositesa.2008.04.013

Brachet, P., L.T. Hoydal, E.L. Hinrichsen and F. Melum, 2008. Modification of mechanical properties of recycled polypropylene from postconsumer containers. Waste Manage., 28: 2456-2464. DOI: 10.1016/j.wasman.2007.10.021 
Da Costa, H.M., V.D. Ramos and M.G. De Oliveira, 2007. Degradation of Polypropylene (PP) during multiple extrusions: Thermal analysis, mechanical properties and analysis of variance. Polymer Testing, 26: 676-684. DOI: 10.1016/j.polymertesting.2007.04.003

Dintcheva, N.T., F.P.L. Mantia, F. Trotta, M.P. Luda and G. Camino et al., 2001. Effects of filler type and processing apparatus on the properties of the recycled "light fraction" from municipal postconsumer plastics. Polymers Adv. Technol., 12: 552-560. DOI: $10.1002 /$ pat. 147

Gupta, V.B., R.K. Mittal, P.K. Sharma, G. Mennig and J. Wolters, 1989. Some studies on glass fiberreinforced polypropylene. Part I: Reduction in fiber length during processing. Polymer Composites, 10: 8-15. DOI: $10.1002 /$ pc.750100103

Homkhiew, C., T. Ratanawilai and W. Thongruang, 2013. Composites from recycled polypropylene and rubber wood flour: Effects of composition on mechanical properties. J. Thermoplast Compos Mater. DOI: 10.1177/0892705712454863

Hugo, A.M., L. Scelsi, A. Hodzic, F.R. Jones and R. Dwyer-Joyce, 2011. Development of recycled polymer composites for structural applications. Plastics, Rubber Composites, 40: 317-323. DOI: $10.1179 / 1743289810$ Y.0000000008

Lawrence, B.C., 2006. Composites for Construction: Structural Design with FRP Materials. 1st Edn., John Wiley and Sons, Hoboken, ISBN-10: 0471681261, pp: 551

Li, H.Y., Y.Q. Tan, L. Zhang, Y.X. Zhang and H. Song et al., 2012. Bio-filler from waste shellfish shell: Preparation, characterization and its effect on the mechanical properties on polypropylene composites. J. Hazardous Mater., 217-218: 256-262. DOI: 10.1016/j.jhazmat.2012.03.028

Lu, J., Q. Wu, I.I. Negulescuf and Y. Chen, 2006. The influences of fiber feature and polymer melt index on mechanical properties of sugarcane fiber/polymer composites. J. Applied Polymer Sci., 102: 5607-5619. DOI: 10.1002/app.24929

Mutje, P., M.E. Vallejos, J. Girones, V. Vilaseca and A. Lopez et al., 2006. Effect of maleated polypropylene as coupling agent for polypropylene composites reinforced with hemp strands. J. Applied Polymer Sci., 102: 833-840. DOI 10.1002/app.24315
Putra, H.D., Y. Ngothai, T. Ozbakkaloglu and R. Seracino, 2009. Mineral filler reinforcement for commingled recycled-plastic materials. J. Applied Polymer Sci., 112: 3470-3481. DOI: 10.1002/app.29861

Serrano, A., F.X. Espinach, J. Tresserras, N. Pellicer and M. Alcala et al., 2014. Study on the technical feasibility of replacing glass fibers by old newspaper recycled fibers as polypropylene reinforcement. J. Cleaner Product., 65: 489-489. DOI: $10.1016 /$ j.jclepro.2013.10.003

Son, J., H.S. Yang and H.J. Kim, 2004. Physico-mechanical properties of paper sludge-thermoplastic polymer composites. J. Thermoplastic Composite Mater., 17: 509-509. DOI: 10.1177/0892705704038471

Tasdemir, M., H. Biltekin and G.T. Caneba, 2009. Investigation of properties of PE and PP / wood flour polymer composites. J. Polymer Sci., 112: 3095-3095.

Velasco, J.I., C. Morhain, A.B. Martinez, M.A. Rodriguez-Perez and J.A. De Saja, 2002. The effect of filler type, morphology and coating on the anisotropy and microstructure heterogeneity of injection-moulded discs of polypropylene filled with aluminium and magnesium hydroxides. Part 1. A wide-angle X-ray diffraction study. Polymer, 43: 6805-6811. DOI: 10.1016/S0032-3861(02)00668-7

Wal, A.V.D., J.J. Mulder and R.J. Gaymans, 1998. Fracture of polypropylene: The effect of crystallinity. Polymer, 39: 5477-5481. DOI: 10.1016/S0032-3861(97)10279-8

Xanthos, M. and KA. Narh, 1998. Product design with glass fiber reinforced polymer blends, with potential applications in recycling. Polymer Composites, 19: 768-780. DOI: $10.1002 / p c .10151$

Xanthos, M., J. Grenci, S.H. Patel, A. Patel and C. Jacob et al., 1995. Thermoplastic composites from maleic anhydride modified post-consumer plastics. Polymer Composites, 16: 204-214.

DOI: $10.1002 / p c .750160304$

Zheng, Y., Z. Shen, C. Cai, S. Ma and Y. Xing, 2009. The reuse of nonmetals recycled from waste printed circuit boards as reinforcing fillers in the polypropylene composites. J. Hazardous Mater., 163: 600-606. DOI: 10.1016/j.jhazmat.2008.07.008 